\title{
COZINHA GEOGRÁFICA:
}

\section{A PROPÓSITO DA TRANSFORMAÇÃO DE NATUREZA EM CULTURA}

- PAULO CESAR DA COSTA GOMES*

- LETICIA PARENTE RIBEIRO**

\begin{abstract}
Quando mais nada subsiste de um passado remoto, após a morte das criaturas e a destruição das coisas, sozinhos, mais frágeis, porém mais vivos, mais imateriais, mais persistentes, mais fiéis, $o$ odor e o sabor permanecem ainda por muito tempo, como almas, lembrando, aguardando, esperando, sobre as ruínas de tudo mais, e suportando sem ceder, em sua gotícula impalpável, o edifício imenso da recordação.[...] tudo isso que toma forma e solidez, saiu, cidade e jardins, da minha taça de chá (M. Proust, No caminho de Swann, p.46-47) ${ }^{t}$
\end{abstract}

RESUMO: ESSE TRABALHO PROCURA DEMONSTRAR A OPORTUNIDADE, 0 INTERESSE E A RELEVÂNCIA DE tRABALHAR GEOGRAFICAMENTE COM A PRODUÇÃO DE ALIMENTOS, PARTINDO DA IDÉAA DAS COZINHAS COMO OFIIINAS DE TRANSFORMAÇ̃O DE NATUREZA EM CULTURA. A FORMA DE ORGANIZAÇÃ̃ ESPACIAL E OS USOS ESPACIAIS - CLASSIFICAÇ̃̃O, TRAJETÓRIAS, PERCURSOS, DIMENSÕES, LOCALIZAÇÃO RELATIVA - DAS COZINHAS PODEM, POR ISSO, CONSTITUIR UM OBJETO DE ESTUDO FUNDAMENTAL PARA A GEOGRAFIA.

PALAVRAS-CHAVE: GEOGRAFIA, CULTURA, PRODUÇÃO DE ALIMENTOS

Não há nenhuma novidade na constatação de que a alimentação, nas mais diversas sociedades e em diferentes tempos, cumpre sempre um papel bem mais complexo do que o simples ato fisiológico de nutrir. No período moderno isso é muito claro, pelo menos, desde a publicação, no começo do Século XIX, do livro de Brillat-Savarin, Physiologie du Goût ${ }^{2}$. Apresentado como um dos 
fundadores da moderna gastronomia, esse autor ficou também famoso pelos aforismos que demonstravam nitidamente o ponto de vista segundo o qual a alimentação é um componente fundamental do repertório de expressão das culturas - "Os animais pastam, os homens comem, mas apenas o homem de espírito sabe comer" ou ainda "O destino das nações depende da forma como elas se alimentam".

Não é, pois, nada surpreendente que as ciências sociais nascentes tenham, desde o início, conferido importância ao estudo do papel simbólico da alimentação e reconhecido valor explicativo nos diferentes hábitos de produção e consumo dos alimentos. Como um elementochave na diferenciação das culturas, os ritos, costumes e simbologia contidos na alimentação foram, por exemplo, desde o início da antropologia um dos campos de predileção das pesquisas etnográficas. Já em Malinowsky, pioneiro desse gênero de estudo, pode ser percebido o valor atribuído à dieta alimentar, assim como à maneira de comer ou de preparar as refeições, para a reprodução social, reprodução física, mas, sobretudo, cultural $^{3}$. Sua discípula, Audrey Richards, inspirada, sem dúvida, nesse ponto de vista, contribuiu decisivamente para fazer dessas observações sobre a alimentação um campo fundamental de estudos na antropologia ${ }^{4}$. Ela argumentava, com razão, que a alimentação e a sexualidade são elementos essenciais na reprodução de um grupo social e, por isso, constituem a base para o entendimento de como esses grupos se organizam. Prova também da importância crescente desse tema foi a publicação, em 1945, pela conhecida antropóloga Margareth Mead, de um manual para o estudo dessas práticas alimentares ${ }^{5}$. Procurava-se assim estabelecer as bases comuns para esse tipo de estudo e recomendava-se que além dos aspectos propriamente antropológicos fossem a eles também associados os aspectos biológicos, psicológicos e socioambientais.

As explicações para os hábitos alimentares até esse momento, no entanto, tendiam, em grande parte, a colocar em foco uma causalidade funcional ou naturalista. As formas de preparação e ingestão dos alimentos nas sociedades eram assim, em última instância, explicadas pela atribuição de finalidades, seja as de ordem natural ou as de ordem cultural.

\section{A ALIMENTAÇÃO ENTRE NATUREZA E CULTURA: O CRU E O} COZIDO

A introdução da perspectiva estruturalista trouxe uma grande inflexão nessa matéria. $\mathrm{O}$ programa de conhecer uma "gramática" das culturas, ou seja, os elementos regulares e gerais em torno dos quais se organiza a variedade de manifestações de um campo qualquer da atividade social, trouxe um novo desenvolvimento possível para os estudos antropológicos sobre a alimentação. A contribuição muito original apresentada por Lévi-Strauss de uma estrutura com três vértices, conhecida como "triângulo culinário", estabelecido pelas posições do cozido, do cru e do podre, foi muito importante e deu um novo horizonte aos estudos na antropologia da alimentação ${ }^{6}$. 
Obviamente, só as sociedades que dominam o fogo criaram a categoria dos alimentos cozidos. Isso revela uma passagem do natural ao cultural, pela transformação do alimento, transformação que permite a ampliação da dieta alimentar e a melhor conservação dos produtos ${ }^{7}$. Segundo o antropólogo, a transição do cru para cozido se efetua por um processo cultural, enquanto o do cru (ou cozido) ao podre se efetiva por processos naturais. Entre esses vértices do triângulo, ocorrem situações intermediárias, por exemplo, o roastbeef, cru no interior e cozido no exterior.

É importante perceber, no entanto, que essas posições não são absolutas e há, por exemplo, situações em que os processos de apodrecimento são "culturalmente" produzidos (como nos queijos franceses, em algumas preparações das carnes ou no famoso ovo chinês dos 100 dias, entre outros). Esses procedimentos indicam assim o controle da cultura sobre os processos naturais, nesse caso do apodrecimento, no essencial provimento alimentar de um grupo social.

Mary Douglas, seguindo Lévi-Strauss, considerava os alimentos como verdadeiros veículos de comunicação, uma língua cuja estrutura pode ser revelada através do emprego da gramática correta $^{8}$. Em seu livro, Purity and danger (1966) ${ }^{9}$, ela mostra que os limites do gosto não são individuais, são determinados por normas culturais, religiosas, de classe, como disse também mais tarde Pierre Bourdieu ${ }^{10}$
UM MITO FUNDADOR

Se aceitarmos, grosso modo, a ideia de Lévi-Strauss de que as categorias de cru e de cozido pertencem às sociedades que dispõem do domínio do fogo, podemos concluir logicamente que desse domínio surge uma palheta de escolhas daquilo que deve ser comido e das formas pelas quais devemos fazê-lo. Através desse eixo fundamental do cru ao cozido, podemos dizer que o processo de preparação e de cozimento dos alimentos, a culinária, compõe um conjunto de operações que simbolicamente transformam natureza em cultura ${ }^{1}$. Por isso, o apodrecimento, que seria o processo natural de degenerescência dos alimentos, se situa em oposição diametral ao cozido somente quando esse processo de apodrecimento não se encontra devidamente retrabalhado pela intenção da cultura (exemplo: o queijo camembert au lait cru).

Daí a importância e a centralidade do mito grego da oferta do fogo aos homens. Prometeu é um titã, cujo nome quer dizer aquele que pensa antes, ao contrário do seu irmão Epimeteu, que significa aquele que pensa depois. Ambos receberam a incumbência de criar os animais e os homens. Epimeteu, como sugere o nome, se precipitou e deu aos animais aquilo que de melhor ele dispunha: força, rapidez, coragem, mas também, plumas para voar, pelos para proteger, conchas para se resguardar etc. Ao chegar a vez de distribuir atributos aos homens, pouco havia sobrado e, dessa forma, só restou a Prometeu 
tentar compensar a falta desses naturais atributos pela oferta do fogo. Prometeu também ensinou aos homens a enganar Zeus. Cobriu as melhores parcelas das carnes dos animais sacrificados com uma pele de um animal velho e doente e optou pela melhor pele para cobrir os ossos e a gordura. Depois, propôs a Zeus escolher entre esses dois conjuntos aquele que, em sua opinião, deveria ser dado aos homens. Através desse estratagema na apresentação das carnes, Prometeu, protegendo os homens, induziu Zeus a fazer uma escolha errada, cabendo assim sempre aos homens as melhores parcelas dos animais sacrificados e sendo ofertados apenas os piores pedaços aos deuses. Como vingança, Zeus enviou aos homens Pandora e sua caixa de coisas ruins (aceita por Epimeteu). Zeus também acorrentou Prometeu nas montanhas caucasianas, aonde uma águia vinha todos os dias comer seu fígado, que se regenerava à noite e perpetuava assim o castigo. Pelo mito de Prometeu se compreende que a criação humana é antinatural, anticósmica $^{11}$. Pelo domínio da técnica, os homens tentam criar, mas eles não são deuses e conseguem apenas transformar a matéria. A civilização é um combate entre a ordem cósmica (natural) e a humana que se estabelece a partir do "presente" de Prometeu. A cozinha não deixa de ser uma importante parcela desse combate humano para sobreviver e conseguir tirar prazer daquilo que é antes uma limitação, uma necessidade natural. Em outras palavras, o ato de cozinhar e prover de alimentos a uma sociedade é parte do cotidiano e renovado combate entre natureza e cultura. Cada refeição constitui assim uma pequena vitória nessa luta.
UMA COZINHA GEOGRÁFICA?

Muitos trabalhos e também muitas críticas já foram feitas a esse sistema do triângulo culinário. Essa longa introdução pode equivocadamente criar a expectativa de que a pretensão desse trabalho seria a de prolongar a discussão sobre a validade ou não desse quadro analítico. Nossas ambições são, entretanto, bem mais modestas.

O que se pretende é simplesmente partir da ideia de que a preparação dos alimentos se inscreve nessa simbologia da transformação da natureza em cultura. Essa ideia funcionará assim como um pressuposto. Nesse caso, como geógrafos, podemos dizer que a cozinha, o local onde se opera essa transformação, é um dos altos lugares onde se elabora essa mutação do natural em cultural. A forma de organização e os usos espaciais - classificação, trajetórias, percursos, dimensões, localização relativa - das cozinhas compõem, por isso, um objeto de estudo fundamental, ainda que muito pouco abordado pela geografia ${ }^{12}$.

Assim, o desenho e a distribuição dos equipamentos e as rotinas dos movimentos e comportamentos espacializados podem ser analisados segundo uma lógica interpretativa que enfatize a trama das localizações e os comportamentos associados a ela. Isso pode ser observado não só nas cozinhas, mas na relação e na circulação que se estabelece entre elas e os salões ou, por exemplo, na ordem dos pratos sobre a mesa (serviço à francesa) ou dos convivas em torno dela, como na sofisticada etiqueta dos grandes salões franceses da época do rei Luiz XV. 
Poderíamos mesmo dizer que, do ponto de vista espacial, há duas diferentes lógicas centrais se considerarmos o consumo ou a produção dos pratos: a primeira rege o universo propriamente da organização da refeição, a posição/disposição dos convivas e das travessas; enquanto a segunda, da preparação dos alimentos, tem como ponto central a organização das mobilidades.

No primeiro caso, a mesa funciona como uma "grade" que permite estabelecer as posições relativas dos convivas (disposição circular, as cabeceiras, as vizinhanças etc.), fixando assim um conjunto de valores associados a essas posições e o acesso diferenciado aos pratos e às outras pessoas. Por outro lado, a apresentação da refeição, servida de uma vez só ou fragmentadamente possibilita uma disposição, um ordenamento espaço-temporal dos pratos, quer pelo sequenciamento, quer pela arrumação na mesa.

Já para a preparação da comida, o espaço interno da cozinha organiza um conjunto de mobilidades e permite sincronizar diferentes movimentos. A transformação operada, desde a seleção dos ingredientes básicos (ação que já supõe separação e classificação) até a montagem final do prato, só se realiza a partir de um conjunto de deslocamentos, envolvendo diferentes suportes, recipientes, instrumentos e superfícies. Diferentes etapas, ou estágios, correspondem a lugares (recipientes e/ou superfícies) distintos. Os corpos dentro da cozinha também devem ser disciplinados e seus movimentos, sincronizados, donde a importância atribuída ao aprendizado dos gestos, que assegura a máxima eficiência no uso do espaço e o controle sobre os tempos de realização das tarefas. No cozinha, o domínio das relações de proximidade espacial é decisivo:

As cozinhas dos restaurantes são conhecidas por serem lugares pequenos e apertados nos quais um movimento errado é o prenúncio de um desastre. É necessário, portanto, uma disciplina considerável: Você se move em uma direção e cronometra seus movimentos para evitar o conflito físico com aqueles que trabalham a sua volta e a seu lado. Você antecipa os movimentos reflexivamente e alcança um timing, uma coordenação e uma precisão comparáveis ao movimento de um relógio suíço. Se for negligente em seus movimentos como chef, cozinheiro, maître, ou garçom, você acaba derramando a sopa no chão. As zonas de conforto entre aqueles que trabalham juntos são sacrificadas nos espaços apertados ${ }^{13}$

As perguntas podem também ser estendidas em relação às rotinas espacializadas das diferentes práticas culturais culinárias. Quais as grandes diferenças organizacionais entre as variadas cozinhas étnicas, reconhecidas como evidências quando comparadas pelo tipo de preparação? As culinárias francesa, indiana, chinesa, japonesa etc. Não se diferenciam somente pelo tipo de alimento, ou por sua apresentação ou receita, se diferenciam também pela forma como se organizam as cozinhas, que podem assim ser consideradas como verdadeiras oficinas de transformação da natureza em cultura. $\mathrm{O}$ reconhecimento da diferença nesses modelos 
organizacionais pode então, sem dúvida, ser um importante elemento de análise e de interpretação.

Pode-se ainda observar que, mesmo nas sociedades ditas ocidentais, há significativas diferenças nessa organização como, apenas para citar um exemplo, no modelo da cozinha integrada (também conhecida como "cozinha americana") ou nos diferentes tipos de serviço, à francesa, à russa, à inglesa ou à americana.

Há uma grande variedade de temas de estudo relacionados à alimentação: rituais, interdições, composições etc. De fato, constata-se que a maior parte dos trabalhos sobre alimentação tende a se concentrar mais nos produtos, nos pratos e receitas, do que nos ambientes físicos que os produzem. Há mesmo uma dificuldade em encontrar referências ou informações precisas e descritivas sobre onde são fabricados os pratos (as diferentes organizações do espaço das cozinhas), o que indica que trabalhar com esses dados demandaria uma verdadeira pesquisa preliminar de coleta de informações que não parecem, em princípio, muito valorizadas como elementos analíticos. Quando a cozinha saiu do ambiente doméstico e passou a ser um domínio do público? Que transformações ocorreram em sua organização física? A cozinha deixa de ser um aposento para se transformar, às vezes, em um estabelecimento comercial e isso é fruto de um longo processo. De forma mais geral, quais as diferenças entre o universo dessa atividade quando praticada na esfera doméstica e quando exercida na esfera pública?

DO DOMÉSTICO AO PÚBLICO
Os restaurantes, tal como os conhecemos atualmente, são uma criação relativamente recente, de meados do Século XVIII. Os modernos restaurantes são estabelecimentos comerciais dentro dos quais qualquer pessoa pode ser admitida e, mediante pagamento, pode escolher, encomendar e consumir alimentos. A concepção que deu origem a esses estabelecimentos, dessa forma organizados, dependeu fundamentalmente do aparecimento do que Habermas denominou como esfera pública ${ }^{14}$. Essa esfera corresponde, simplificadamente, a um conjunto de indivíduos, de pessoas privadas, dotadas de mobilidade, com direito à acessibilidade, informadas e comcapacidade crítica. Da comunicação advinda dos debates e da ação crítica desse conjunto de indivíduos e da frequência de lugares comuns, tanto no sentido material, (praças, restaurantes, salões, cafés, restaurantes etc.) como no sentido imaterial, (jornais, televisão, rádios, internet etc.), surge a opinião pública. Restaurantes são, portanto, lugares de frequência de um público reunido em torno da ideia do consumo de alimentos, de refeições, mas são também lugares de convívio, de encontro, enfim de atividade do homem público.

São por isso estabelecimentos regulados por normas e convenções que regem esse universo do público. Isso corresponde a dizer que a organização desses lugares obedece aos preceitos que regem a vida pública e, nesse sentido, o ato de se alimentar nesse espaço traduz em sua organização os valores e as regras da própria vida pública. De fato, na maior parte dos restaurantes, o acesso deve ser livre e indiscriminado 
(obedecendo-se às restrições cabíveis a esse tipo de estabelecimento), a conduta se assemelha àquela prevista para todos os consumidores que fazem escolhas individualizadas de acordo com as opções que lhes são oferecidas. O serviço deve ser assegurado segundo horário previamente estabelecido e deve ser garantido de forma individualizada e não discriminatória. $\mathrm{O}$ cliente é recebido no salão, composto de mesas e cadeiras não muito distinguidas entre elas. Nesse salão, onde são servidos os pratos, há uma separação física, ambiental e simbólica da cozinha onde os alimentos são preparados.

Entre esses dois espaços a ligação é assegurada por pessoas associadas ao serviço e pelo cardápio que deve informar sobre a escolha dos pratos e dos preços. Esse serviço, em geral, conta com um gerente (maître d'hotel), com os garçons encarregados de servir os pratos e os ajudantes (limpam as mesas, servem o pão, arrumam a sequência dos pratos etc), pode haver também no salão o atendimento do sommelier para a escolha dos vinhos.

As cozinhas desse tipo de restaurantes mais comuns são divididas em setores e, se pertenceram a grandes restaurantes, contarão com pessoas diferentes responsáveis por tarefas diversas: o chef, comandante principal, e seu ajudante imediato o sous-chef e os responsáveis por áreas específicas, dos grelhados, dos acompanhamentos, dos molhos, das sobremesas etc. E seus ajudantes (cortadores, lavadores etc.). Essa hierarquia é associada a signos da indumentária e/ou equipamentos (cor e modelo das roupas, toque, máscara, touca, luvas etc.) $\mathrm{O}$ prato deverá circular entre essas diversas áreas à medida que está sendo confeccionado e ao final, em sua última passagem, será visto pelo mais alto da hierarquia que o libera para o salão.

O universo organizacional de um restaurante se assemelha assim a uma hierarquia de um corpo profissional bastante especializado. A analogia mais próxima é a da indústria, com suas turmas dispostas por categorias e organizadas segundo setores e tarefas. Tal qual nos modelos industriais de produção em série, o produto circula pelas áreas e pelas turmas até ser, finalmente, acabado para ser apresentado ao consumidor. É importante organizar os fluxos de atividade pelo espaço, evitando todo e qualquer cruzamento. Importante também é separar circuitos para preservar a segurança e garantir a higiene. $\mathrm{O}$ ambiente físico das cozinhas muitas vezes se assemelha ao de uma usina, com linhas e percursos induzidos, Elas são também, muitas vezes, ladrilhadas e têm comumente o mobiliário de aço inoxidável, o que contribui para dar uma impressão fabril ao lugar. Em geral, essas cozinhas apresentam também grandes equipamentos de conservação, de cozimento e outras máquinas e nas bancadas encontram-se os instrumentos e utensílios diversos. Tudo isso coopera para criar na cozinha um ambiente de eficiência, qualidade, controle - uma usina onde a gestão e a ordem colaboram para a qualidade do produto final.

Esse modelo de estabelecimento característico das sociedades ocidentais urbanoindustriais teve como precursores os chamados auberges ou tables d'hôtes, onde se serviam refeições em horário fixo, em grandes mesas 
comuns e sem escolha dos pratos. No Brasil, essa modalidade é também conhecida como "pensão". É importante perceber que nesses predecessores dos modernos restaurantes ainda havia, na base, a aparência doméstica e familiar. A comida é servida como se fossem recebidos "convidados", as pessoas são em geral conhecidas (poder-se-ia dizer, familiares), em alguns casos as pessoas podem se servir na própria cozinha, e o modelo organizacional da cozinha é ainda o mesmo que prevalecia nas casas privadas, mudando-se talvez um pouco as dimensões e escalas.

A separação entre os ambientes, da cozinha para a sala, existia também, porém talvez muito mais envolvida com a ideia de gradação de intimidade dentro de um ambiente doméstico (familiar). A ruptura no restaurante é mais consistente entre o ambiente produtor, organizado segundo um modelo industrial e o ambiente consumidor, assemelhado a um grande de salão, festivo e público.

Além do legado das cozinhas domésticas, certamente, as cozinhas dos modernos restaurantes prolongam muito mais as tradições das velhas cozinhas senhoriais, entre elas a hierarquia e a especialização

La cuisine est l'affaire des femmes dans les milieux populaires. Mais, dans les vastes cuisines spécialisées des seigneurs et des princes, un univers très hiérarchisé d'hommes veille à l'approvisionnement et à la préparation des repas pour une maisonnée nombreuse. [...] Dans les cuisines spacieuses et bien équipées des grands s'active un monde d'hommes très hiérarchisé: queux, "hasteurs" chargés des rôts, potagiers, sauciers, qui doivent rendre compte de leur cuisine comme de leurs dépenses. Ils sont aidés par une ribambelle de jeunes galopins de cuisin ${ }^{15}$.

De fato, essas cozinhas eram verdadeiras oficinas e, como bem disse Sennett, estas podem ser definidas como "um esforço produtivo no qual as pessoas lidam diretamente com questões de autoridade (...) atentas às capacitações como fonte de legitimidade do comando ou de dignidade da obediência" ${ }^{\prime 16}$. Assim, talvez seja possível conceber o modelo dessas modernas cozinhas dos restaurantes a partir de uma continuidade com o padrão das oficinas manufatureiras, hierárquicas, pedagógicas, preservadoras de um savoir faire, que as qualifica. Tal qual se passou em outros terrenos de atividade produtiva, passamos de um modelo artesanal, manufatureiro a um molde industrial. $\mathrm{O}$ aspecto doméstico, quando hoje aparece nessa atividade da restauração, é talvez muito mais o resultado de um apelo comercial do que verdadeiramente tradução de um modelo de produção.

É necessário ainda perceber que a passagem do modelo manufatureiro para um modelo industrial nessas cozinhas não subtraiu um componente fundamental das oficinas: a dimensão artística. Os produtos aí criados testemunham a distinção e a qualidade desses artífices. Muitas vezes, essa qualidade é, aliás, atribuída a pequenos segredos ou à especial destreza na produção dessas obras. Essa dimensão também se encontra na arte da cozinha dos grandes restaurantes atuais.

A OBRA DE ARTE E A EXPOSIÇÃO 
Insistindo no pressuposto que alicerça nossas observações, ou seja, o de que a cozinha constitui um atelier onde se produz a transformação de natureza em cultura, podemos dizer que o produto daí derivado pode, com facilidade, ser elevado a uma dimensão estética superior. A cozinha e seus produtos, seus pratos e sua ritualística podem ser vistos como genuínas obras de arte. Na verdade, se esse for o caso, essas obras têm como expressividade justamente a valorização desse trabalho de transformação de natureza em cultura.

Um personagem surgido na modernidade nos ajuda a compreender como a cozinha deixou de ser uma atividade trivial para a alimentação e foi alçada ao mais alto grau de distinção, o de uma obra de arte. Esse personagem é o crítico gastronômico. Essa figura do crítico é típica de um momento - a modernidade - no qual a atividade crítica é identificada como um dos pilares fundamentais da vida pública e atributo essencial do homem moderno. Se pensarmos bem, só há sentido de existir um crítico gastronômico se sairmos do estrito universo da sensibilidade do gosto para uma esfera mais complexa da estética. Como diria Kant, gosto não se discute, mas se disputa $^{17}$. Se permanecermos na esfera da subjetividade do sabor individual, não há sentido em se exercitar a crítica gastronômica, posto que cada um sente de uma forma e prefere se alimentar de uma maneira própria. Mas se a alimentação em nossa sociedade tem como um dos seus principais significados a metaforização do valor positivo da luta humana em sua transformação da natureza, então, nesse sentido, a cozinha, a gastronomia, é muito mais do que uma questão de gosto. Trata-se de um domínio estético, de arte, atividade humana capaz de transmitir sensações, emoções e conteúdos. Por isso, ainda que por vezes considerada como uma arte menor, a gastronomia pode ser erguida ao domínio estético e, o mais importante para nós aqui, isso é possível pois ela representa de alguma forma a positiva transformação da natureza em cultura.

Um paralelo é possível com a ideia de paisagem e seu valor estético. A paisagem é admirável pelo espetáculo que propicia. Ela coloca em cena a obra humana de transformação da natureza, resultado da laboriosa atividade de uma cultura sobre a natureza. Uma paisagem é também admirada pelo prazer que sua simples contemplação oferece. A imensa iconografia de paisagens se nutre assim dessa ideia de um ponto de vista privilegiado, a partir do qual se abre um cenário que desperta nosso prazer, seja ele sensitivo, prazer visual, seja ele fruto de uma admiração diante da força humana de criar novos ambientes. A partir daí são pintados quadros, são feitas fotografias, cartões postais, descrições textuais etc. As paisagens e seus valores associados são fixados em produtos, em obras de arte.

Talvez o mesmo possa ser dito a propósito comida. Alimentos e suas preparações podem ser fixados em produtos, em imagens, em pratos, em discurso. Podem ser apreciados como uma espécie de síntese, como uma estetização do trabalho humano e de sua engenhosidade em transformar a natureza, como uma sofisticação do gosto que se afasta da simples necessidade nutricional para desenvolver uma verdadeira linguagem. Podem 
também ser apreciados pelo simples prazer visual da contemplação. $\mathrm{O}$ reconhecido sucesso dos diferentes programas televisivos que nos ensinam ou nos demonstram a arte de bem cozinhar reside talvez nessa fórmula simples, união da pedagogia do gesto e da receita, unido à prazerosa contemplação da confecção de uma obra de arte, um prato.

As naturezas mortas são também uma prova disso. A representação pictórica de composições de frutas, flores, legumes e, às vezes, carnes é bem conhecida desde a Antiguidade e aparece em muitos mosaicos ou pinturas murais greco-romanos. A criação de um gênero de pintura associado a esse tipo de representação é, no entanto, bem mais recente. A estabilização do gênero, assim como sua denominação, surge no mesmo local e na mesma época que o gênero das paisagens, na Holanda do Século XVII ${ }^{18}$. A natureza morta e as paisagens são temas burgueses por excelência, em oposição à pintura de origem aristocrática e religiosa. Esses temas colocam em relevo o cotidiano, a dimensão humana e, muitas vezes, guardam o virtuosismo da "imitação da natureza", acrescentando aos temas, pelas composições e pelas associações, a sublime presença da humanidade nos objetos de origem natural. Frutos em diferentes momentos de maturação, às vezes até apodrecidos, insetos, facas, caveiras, livros, há toda uma série de sistemas metafóricos nessas representações que falam dos ciclos da vida, da efemeridade das coisas, dos limites naturais da existência, da grandeza do cotidiano, do prazer da simplicidade etc. Hoje, nas atuais condições de supervalorização de imagens, somos cotidianamente expostos a infinitas cenas de apresentação de comidas, pratos e produtos alimentares. Fotos, publicidades, vitrines, balcões: a comida é quase onipresente em nosso dia a dia, solicitando nosso olhar, nosso olfato e nosso paladar. Mais uma vez, como geógrafos, podemos nos indagar se essas cenas não seguem determinados padrões espaciais para a exposição em que lugares e em que situações? O tipo de exposição muda de acordo com os lugares? Que associações são construídas entre os lugares e as formas de apresentação desses produtos?

UM DIGESTIVO OU UM APERITIVO?

Não pretendíamos nessa breve apresentação responder a todas essas questões. Isso, sem dúvida, constitui um objeto de pesquisa que demandaria muito maior dedicação, levantamento de muitos outros dados, contemplação de muitos outros assuntos correlatos etc. Queríamos simples e fundamentalmente atender a um duplo objetivo com essa apresentação.

Em primeiro lugar queríamos demonstrar que, a despeito do interesse, há uma relativa ausência dos geógrafos nessa pauta ${ }^{19}$. São, sem dúvida, bastante conhecidos e relativamente bem estudados muitos aspectos interessantes sobre a forma de consumo dos alimentos e as culturas ${ }^{20}$. Sabe-se também bastante sobre a construção antropológica e cultural do gosto, como, por exemplo, da importância das diferentes texturas na comida chinesa como uma obediência ao contraste das ordens relativas ao Yin e ao Yang. Sabe-se 
também da preferência dessa culinária pela apresentação compósita dos elementos nos pratos que só com muita dificuldade podem ser identificados e individualizados. Ao contrário, na sofisticada culinária francesa, muitas vezes, partes da morfologia original dos alimentos são conservadas e/ou apresentadas como figurações o que já levou alguns a dizerem que os franceses comem inteiras as mesmas coisas que os chineses comem em pequeníssimos pedaços. Hoje o auge do refinamento é a apresentação do prato pronto e dressé (elaborado), em contraposição ao ideal de fartura e variedade das grandes mesas nobres dos séculos XVI e XVII ${ }^{21}$ ou, atualmente, em oposição ao ideário das mesas mais populares. Alguns grandes pensadores brasileiros também já se dedicaram ao tema. Desde o pioneirismo da obra de Câmara Cascudo $^{22}$, passando por Gilberto Freyre $^{23}$, e chegando a Roberto da Matta ${ }^{24}$ as relações entre a "brasilidade" e a produção de alimentos no Brasil já foram bastante contempladas. Para esse último, aliás, o cozimento em conjunto e misturado e uma dominante consistência intermediária dos principais pratos brasileiros constitui uma estrutural opção pelo meio-termo, traço típico da cultura brasileira. Muito pouco, no entanto, se encontra sobre o ambiente físico desses lugares, sua organização e suas transformações.

Em segundo lugar, nosso objetivo carrega uma grande ambição que é a de demonstrar como o raciocínio geográfico é original e importante quando bem aplicado. Ele não se confunde com as outras áreas de interesse. Esse raciocínio geográfico deve guardar suas marcas específicas e, da diferença de sua curiosidade e de suas questões, mostrar seu alcance e sua relevância. A geografia assim concebida pode, sobretudo, entrar em cooperação sem se fundir e se confundir com outras disciplinas. Tudo depende em grande parte da forma como construímos as questões. Se elas forem precisas e mantiverem o compromisso com uma explicação que coloque em relevo a ordem espacial dos fenômenos, teremos cumprido grande parte do desafio. Por isso, podemos dizer que na constituição de um saber científico construir as questões é mais do que meio caminho andado, talvez seja mesmo o essencial. Foi esse exercício que nos mobilizou nessa breve viagem pelo mundo da gastronomia. Esperamos ter conseguido sensibilizar o apetite de pelo menos alguns quanto à importância da geografia também em respeito a esse tema.

SOBRE OS AUTORES

*Professor Dept ${ }^{\circ}$ de Geografia, UFRJ

**Professora Dept ${ }^{\circ}$ de Geografia, UFRJ

NOTAS

${ }^{1}$ Proust, Marcel. Du côté de chez Swann. Paris: Folio, 1987.

${ }^{2}$ BRILlAT-SAVARIN, Jean A. Fisiologia do gosto. São Paulo: Cia. das Letras, 1995.

3 MALINOWSKI, Bronislaw. Introdução. In: Os argonautas do Pacífico Ocidental. São Paulo: Abril, 1978.

${ }^{4}$ RICHARDS, Audrey I. Hunger and work in a savage tribe: a functional study of nutrition among the Southern Bantu. Londres:Routledge 1932. 
${ }^{5}$ MEAD, M.; Guthe, C.E. Manual for the study of food habits. Bulletin of the National Research Council, National Academy of Science, $\mathrm{n}^{\circ} .111,1945$.

${ }^{6}$ Lévi-Strauss, Claude. Le cru et le cuit. Paris:Plon, 1964.

${ }^{7}$ A relação entre nutrição e sistema orgânico é muito antiga e atua como base de muitas teorias da saúde. Não estamos contemplando esse tipo de relação entre natureza e cultura, associado às crenças e aos tabus. Por isso, outras oposições de alimentos em categorias antinômicas como o puro e o impuro, fortes e fracos, quentes ou frios, embora participem da visão estruturalista, não são objeto de nossa análise.

${ }^{8}$ Mary Douglas foi aluna e seguidora de Edward Evans-Pritchard. Contudo, na década de 1960, foi fortemente influenciada pela leitura de Lévi-Strauss e isso aparece de forma clara em seu livro de 1966.

${ }^{9}$ DOUGLAS, Mary. Pureza e perigo. São Paulo: Perspectiva, 1976.

10 OURDIEU, Pierre. Distinction.Pratique socialedujugement. Paris:Minuit, 1979.

${ }^{11}$ Simbolicamente, pois, significa muito mais a migração de uma região da cultura para outra: os alimentos são fruto de uma agricultura. O fato é que eles ganham um novo estatuto pela passagem que cumprem na cozinha e ganham também, além das transformações físicas, uma nova dimensão estética.

${ }^{12}$ A exceção é o geógrafo francês Jean Robert Pitte que escreveu, entre outras obras sobre o tema, Gastronomie française. Histoire et géographied'une passion. Paris:Fayard, 1991 e Histoire et géographie $\mathrm{du}$ restaurant. In I:CHEVRIER, F. Histoire et nourritures terrestres.Les rendez vous de l'histoire. Blois: CEPH, 2000.

${ }^{13}$ FINE, Gary Alan. Kitchens: The Culture of Restaurant Work. Berkeley e Los Angeles: University of California Press, 1996, p. 81

${ }^{14}$ HABERMAS, Jurgen. Mudanças estruturais na esfera pública. Rio de Janeiro: Tempo Brasileiro, 1986.

${ }^{15}$ Gastronomie Médiévale. Bibliothèque Nationale de France. Expositions Virtuelles. http://expositions.bnf.fr/gastro. Acesso em $04 / 2010$
Tradução: "A cozinha é negócio de mulheres nos meios populares. Mas nas vastas cozinhas especializadas dos senhores e dos príncipes, um universo muito hierarquizado de homens cuida do fornecimento e da preparação das refeições para numerosas pessoas [...]. Nas cozinhas espaçosas e bem equipadas dos grandes homens se agita um muito hierárquico mundo de homens: chefes, "hasteurs" responsáveis por assados, sopeiros, molheiros, que respondem pela cozinha e pelos custos. Eles são assistidos por um grupo de jovens garotos de cozinha".

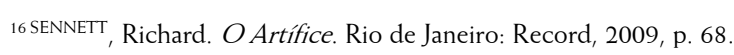

${ }^{17}$ KANT, Immanuel. Critique du jugement: suivie des observations sur le sentiment du beau et du sublime. Vol II. Paris: Vrin, 1986.

${ }^{18}$ A esse respeito ver STERLING, Charles. La nature morte de I'Antiquité au XXe siècle. Paris: Macula, 1985 e GOMBRICH, E. H. A história da arte. Rio de Janeiro: LTC, 1999.

19 Não incluímos Josué de Castro nesse grupo, pois, embora identificado como geógrafo, ele tinha uma formação médica e se ocupou muito mais da questão da fome como problema socioeconômico, derivado do subdesenvolvimento.

${ }^{20}$ Esse tema é bastante estudado. O próprio Lévi-Strauss tem um livro sobre o tema (L'origine des manières à table. Paris: Plon, 1968). Também é muito conhecido o relato histórico que faz disso Elias, Norbert em $O$ processo civilizador (2 vol. Rio de Janeiro:Zahar, 1995).

${ }^{21}$ A fartura, a variedade, o desperdício, tão prezados em muitos momentos da história humana, formam a ideia de "comer heróico" trazida por Fernandez-Armesto em contraposição à sofisticação do gosto e à economia sintética das apresentações atuais. FERNANDEZARMESTO, F. Comida: uma história. Rio de Janeiro: Record, 2004.

${ }^{22}$ CASCuDO, L. C. História da alimentação no Brasil. Rio de Janeiro: Editora Nacional, 1968.

${ }^{23}$ FREYRE, G. Açúcar: uma sociologia do doce com receitas de doces e bolos do Nordeste do Brasil. São Paulo: Companhia das Letras; 1968.

${ }^{24}$ DA MATTA, Roberto. O que faz o Brasil, Brasil? Rio de Janeiro: Rocco, 1997 
ABSTRACT: THIS PAPER SEEKS TO DEMONSTRATE THE TIMELINESS, RELEVANCE AND INTEREST TO WORK WITH GEOGRAPHICALLY FOOD PRODUCTION, STARTING FROM THE IDEA OF KITCHENS AND WORKSHOPS TRANSFORMATION OF NATURE INTO CULTURE. THE FORM OF SPATIAL ORGANIZATION AND USES SPACE-CLASSIFICATION, PATHWAYS, ROUTES, DIMENSIONS, POSITION ON-THE KITCHENS MAY THEREFORE BE A FUNDAMENTAL OBJECT OF STUDY FOR GEOGRAPHY. KEYWORDS: GEOGRAPHY, CULTURE, FOOD PRODUCTION 